\title{
PREDICTORS OF EMPLOYEE ENGAGEMENT IN MALAYSIA, AND THE MODERATING EFFECTS OF JOB DEMANDS AND TOTAL REWARD
}

\author{
Akmal Latiff Ayob*, and Norzanah Mat Nor \\ Arshad Ayub Graduate Business School, Universiti Teknologi MARA, \\ 40450 Shah Alam, Selangor, Malaysia \\ *Corresponding author: akmal@pjh.com.my
}

Published online: 25 October 2019

To cite this article: Ayob, A. L., and Mat Nor, N. (2019). Predictors of employee engagement in Malaysia, and the moderating effects of job demands and total reward. Asian Academy of Management Journal, 24(Supp. 2), 33-49. https://doi.org/10.21315/ aamj2019.24.s2.3

To link to this article: https://doi.org/10.21315/aamj2019.24.s2.3

\begin{abstract}
As reported by Aon Hewitt in 2015 and 2017, there are still a lot of countries, including Malaysia, that recorded the employee engagement score below the global average value of $65 \%$. Malaysia's employee engagement score values were recorded at $61 \%$ and 59\% for years 2015 and 2017, respectively. Low quality condition of new vehicles produced by Malaysia's national automotive manufacturing companies is potentially caused by non-engaged employees. In academic literature, Job Demand-resource $(J D-R)$ is the most widely used theory in employee engagement study. However, there are still a few gaps associated with the theory (i.e., inconsistence finding). In addressing the research gaps, this present study aims to examine whether job-related variables (i.e., job characteristics and job demands), personal-related variable (i.e., positive psychological capital), and environmental-organisational related variable (i.e., total reward) influence employee engagement. The relationships among the variables were explained using two selected theories, namely the JD-R theory, and Self Determination theory. This study makes several significant contributions to practitioners and theories especially on the employee engagement context. Generally, findings from the study significantly contributed knowledge to practitioners especially from Malaysia's national automotive manufacturing companies on the major factors influencing employee engagement for them to understand, describe, and explain. In addition, for the theories, the study added to the general body of knowledge and current research work on the effects of job-related variables
\end{abstract}

(C) Asian Academy of Management and Penerbit Universiti Sains Malaysia, 2019. This work is licensed under the terms of the Creative Commons Attribution (CC BY) (http://creativecommons. org/licenses/by/4.0/). 
(i.e., job characteristics and job demands), personal-related variable (i.e., positive psychological capital), and organisational-environmental related variable (i.e., total reward) on employee engagement.

Keywords: employee engagement, job characteristic, positive psychological capital, job demands, total reward

\section{INTRODUCTION}

Employee engagement becomes a focus amongst both practitioners and scholars due to its positive relationship with organisational performance. From a practitioner's point of view, as highlighted by Aon Hewitt (2017), engaged employee consistently demonstrates three attributes, namely Say, Stay, and Strive, which potentially improve organisational performance. Say is about employee behaviour to consistently speak positively about the organisation to co-workers, potential employees, and customers. Stay is about employee behaviour to consistently have an intense sense of belonging and desire to be a part of the organisation. Strive is about employee behaviour to consistently motivate and exert effort towards success in his or her job and for the company. For Malaysia's national automotive manufacturing companies to successfully achieve the objectives stated in the National Automotive Policy (NAP) 2014, they need engaged employees. An engaged employee should be $100 \%$ psychologically committed to his or her work (Gallup, 2017). From academic point of view, worldwide scholars continue to study and understand how and why the employee engagement emerges, and what impact it has to organisation (Guest, 2014). Currently, definition of concept given by Bakker and Demerouti (2007) and their Job Demand-resource (JD-R) theory has become the most widely used in academic study of employee engagement. Malaysian scholars also demonstrated their interest to study the antecedents of employee engagement from various local industries such as manufacturing, hospitality, and education. Job related variables, personal related variables, and organisational and environmental variables serve as the antecedents of employee engagement.

\section{GAPS, OBJECTIVES, AND QUESTIONS}

The authors have identified a few gaps or problems from practical and theoretical point of view regarding employee engagement. Gaps to be solved in this study were further discussed as follows. 
First, from a practitioner's point of view, there is a difference of employee engagement score percentage among countries compared with the global average score. According to the report by Aon Hewitt, for years 2015 and 2017, there are still a few countries including Malaysia with employee engagement below than global average value of $65 \%$. In 2015, Malaysia recorded $61 \%$ employee engagement score, lower than other countries such as Singapore $(65 \%)$, Thailand (68\%), Philippines (75\%), India (72\%), and China (70\%). In 2017, the score declined to $59 \%$ which was far below than global average score of $65 \%$, and lower than other countries such as India (69\%), China (67\%), Thailand (65\%), Philippines (65\%), and Indonesia (61\%).

Second, also from a practitioner's point of view, there is a difference between the mission stated in Malaysia National Automotive Plan (NAP) 2014 which is to safeguard consumers' interest with safer and better-quality products at competitive prices (Wad \& Govindaraju, 2011) with the current low-quality conditions of new vehicles produced. According to the Malaysia National Consumer Complaints Centre (NCCC), complaints related to automotive were always among the highest in term of numbers and total potential loss to complaints. As summarised and tabulated in Table 1, total numbers of complaints on automotive in six consecutive years started from 2011 were 24,375 cases involving a total dispute values of RM231,054,411.83. Complaints involving faulty in new cars were recorded at 8,777 cases. All these symptoms point to production as a likely problematic area. Although having a lot of problems in this production area may not sound very positive, in this study, authors postulated that it can be very helpful in pointing out the direction to one problem in need of attention and improvement-employees. Low quality of new vehicles produced by Malaysia's national automotive manufacturing companies is potentially caused by non-engaged employees. As noted in Kahn (1990), non-engaged employees promote lack of connections, physical, cognitive and emotional absence, passive and incomplete role performance. In turn, will affect the organisational performance in term of higher turnover and lower productivity.

Despite JD-R theory being claimed as the most widely used theory in academics' study of employee engagement, the authors identified a few problems or gaps associated with this theory. In the following paragraphs, authors discuss in details gaps found in the academic literature regarding JD-R theory, which also include discussion gaps in employee engagement studies within Malaysia context. 
Table 1

Summaries of complaints from Malaysia NCCC report

\begin{tabular}{lccc}
\hline Year & $\begin{array}{c}\text { Numbers of } \\
\text { complaints }\end{array}$ & $\begin{array}{c}\text { Value involved in the } \\
\text { dispute (RM) }\end{array}$ & $\begin{array}{c}\text { Number of cases of new } \\
\text { car faulty }\end{array}$ \\
\hline 2016 & 3,874 & $79,181,869.00$ & 389 \\
2015 & 3,816 & $81,065,376.00$ & 480 \\
2014 & 3,492 & $25,112,522.50$ & 381 \\
2013 & 4,915 & $22,182,476.30$ & 2,639 \\
2012 & 2,986 & $9,544,831.80$ & 1,385 \\
2011 & 5,292 & $13,967,336.23$ & 3,503 \\
\hline Total & 24,375 & $231,054,411.83$ & 8,777 \\
\hline
\end{tabular}

Third, from a theoretical point of view, there are contradictory or inconsistent findings on the roles of job demands in the studies of employee engagement which used JD-R theory to explain the relationship among variables in their theoretical framework. According to JD-R theory, job demands occur when aspects of the job require sustained physical, and/or psychological effort, and are therefore associated with certain physiological and/or psychological costs (Bakker \& Demerouti, 2014). But, as highlighted in Yanchus et al. (2013), research using JD-R theory found the difference between various types of job demands relative to employee engagement. For instance, studies by Upadyaya, Vartiainen and Salmela-Aro (2016), Bakker (2015), Mache et al. (2014), Yanchus et al. (2013), and Bakker, Schaufeli and Hox (2009) found that job demands are not necessarily negative, but they may only turn into job stressors when meeting those demands requires additional effort while the employee has not adequately recovered from previous work sequences. In other study, Bakker (2015) highlighted that, consistent with the boosting hypothesis of the JD-R model, research has shown that the combination of high challenge demands and high job resources particularly fosters employee work engagement. In addition, Demerouti and Bakker (2011) highlighted that the differentiation between "challenge" and "hindrance" job demands is valid still unknown as there is not sufficient empirical evidence on this issue. Moreover, whether the differentiation between these two kinds of demand is valid for every job is still unclear.

Fourth, from a theoretical point of view, little is known about the moderating roles of job demands on the personal resources (i.e., positive psychological capital). As highlighted in Bakker and Demerouti (2014), there is still limited evidence on the interaction between personal resources and job demands. In a discussion by Bakker and Demerouti (2014), findings from a study to test the boosting effect of personal resources hypothesised that weekly emotional job demands could facilitate the 
positive impact of personal resources (self-efficacy and optimism) on weekly work engagement. Using a sample from 63 nurses to fill in a questionnaire at the end of the working week for three consecutive weeks, the results from hierarchical linear modelling showed that emotional job demands strengthened the effect of personal resources on weekly work engagement, confirming that these demands act as a challenge demand for nurses who particularly enjoy caring for other people.

Fifth, from a theoretical point of view, in the academic literature, authors found plenty of studies that sought to examine the antecedents of employee engagement using different conceptual frameworks (e.g., Ahlowalia, Tiwary \& Jha, 2014; Mehta \& Mehta, 2013; Markos \& Sridevi, 2010). However, majority of these studies have focused on samples in Western countries. Despite the benefits of their findings in both academia and practice, empirical evidence on employee engagement in different employment sectors and cultural samples other than the West remains unclear. In addition to this condition, literature works from Malaysia also demonstrated limited evidence on the use of JD-R theory despite it being the most used theory in employee engagement studies worldwide. Authors also found that the existing Malaysia studies fall short of investigating the forms of employee engagement and factors that influence employee engagement categorised as personal-related, job-related, and organisational-environmental related variables combined in one theoretical framework.

Sixth, from a theoretical point of view, after reviewing the literature works on JD-R theory, operationally, two processes are independently involved in the JD-R theory. First, a health impairment process which explained the "combined effect" from the interaction between job demands and job resources may have on employee wellbeing, and will indirectly influence engagement of employee at work. Second, a motivational process which explained how and why job resources and personal resources influence engagement. However, from the best of authors' knowledge through reviewing the literatures on JD-R, the theory did not discuss ways to increase the job resources (i.e., job characteristics) and personal resources (i.e., positive psychological capital) for employees to face the higher job demands. Due to the gaps, it is logical for authors to introduce a new variable (i.e., total reward) as a moderator in the JD-R model to give moderating effects on the job characteristics and positive psychological capital as focal variables. In turn, employees can confront job demands, and engage with their work.

Taken together, the general objective for this study is to contribute to the general body of knowledge and research work in the effects of job-related variable (i.e., job characteristics and job demands), personal-related variables (i.e., positive psychological capital), and organisational and environmental-related variable (i.e., total reward) on employee engagement. 


\section{SELECTED VARIABLES FOR STUDY}

According to the gaps in the practitioners and academic areas as discussed in the problem statement, employee engagement becomes the variable of primary interest (i.e., dependent variable). Authors' goal is to understand and describe (i.e., to explain variability, or predict it) the dependent variable. In other words, in this study, dependent variable (i.e., employee engagement) is the main variable that lends itself for investigation as a viable factor. Through the analysis of the dependent variable to find what variables influence it, it is possible for authors to find answers or solution to the problem. Then, authors conducted literature review before selecting variables to study. Authors decided to select variable(s) to study based on two criteria. First, the variable(s) should be scientifically proven, from previous studies, to influence employee engagement. Second, the variable(s) can be explained using the selected theories. There were four selected variables to study, namely job characteristics and job demands to represent job-related variables, positive psychological capital to represent personal-related variable, and total reward to represent organisational-environmental related variable. The relationships or interconnections among these variables were explained by two theories, namely JD-R theory, and Self Determination theory.

\section{Employee Engagement}

Authors adopted a concept given by Schaufeli et al. (2012) where they defined engagement of employee at work, termed as "work engagement" as "a positive, fulfilling, work-related state of mind that is characterized by vigour, dedication, and absorption." Vigour is characterised by high levels of energy and mental resilience while working, the willingness to invest effort in one's work, and persistence even in the face of difficulties. Dedication refers to being strongly involved in one's work and experiencing a sense of significance, enthusiasm, inspiration, pride, and challenge. Absorption is characterised by "being fully concentrated and happily engrossed in one's work, whereby time passes quickly, and one has difficulties with detaching oneself from work."

\section{Job Characteristics}

Job characteristics refer to attributes of a job that can have motivational functions for employees (Hackman \& Oldham, 1976). As explained by Job Characteristics model, job characteristics consist of five core job dimensions, namely skill variety, job identity, job significance, job autonomy, and job feedback seen as prompting three psychological states of employee, which are experiencing meaningfulness of the work, responsibility for the outcomes of the work, and knowledge of the results 
of the work activities. These, in turn, influence positive work outcomes (e.g., job satisfaction, absenteeism, work motivation, and engagement).

Skill variety refers to the degree to which a job requires a variety of different activities in carrying out the work, which involves the use of a number of different skills and talents of the person (Hackman \& Oldham, 1976). Job identity refers to the degree to which the job requires completion of a "whole" and identifiable piece of work; that is, doing a job from beginning to end with a visible outcome (Hackman \& Oldham, 1976). Job significance refers to the degree to which the job has a substantial impact on the lives or work of other people, whether in the immediate organisation or in the external environment (Hackman \& Oldham, 1976). Job autonomy refers to the degree to which the job provides substantial freedom, independence, and discretion to the individual in scheduling the work and in determining the procedures to be used in carrying it out (Hackman \& Oldham, 1976). Job feedback refers to the degree to which carrying out the work activities required by the job results in the individual obtaining direct and clear information about the effectiveness of his or her performance (Hackman \& Oldham, 1976).

\section{Positive Psychological Capital}

Positive psychological capital refers to the individual motivational propensities that are accrued through positive psychological constructs of self-efficacy, optimism, hope, and resilience (Luthans \& Youssef, 2007). Hope refers to individual's positive psychological state characterised by persevering toward goals and redirecting paths to goals in order to succeed (Luthans \& Youssef, 2007). Selfefficacy refers to individual's positive psychological state characterised by having confidence to take on and put in the necessary effort to succeed at challenging tasks (Luthans \& Youssef, 2007). Resilience refers to individual's positive psychological state characterised by the capacity to rebound or bounce back from adversity, conflict, failure or even positive events, progress and increased responsibility (Luthans \& Youssef, 2007). Optimism refers to individual's positive psychological state characterised by making a positive attribution about succeeding now and in the future (Luthans \& Youssef, 2007). Optimists are those who expect good things to happen (Youssef \& Luthans, 2007).

\section{Job Demands}

In this study, authors defined job demands according to the JD-R model introduced by Bakker and Demerouti (2007). Job demands refer to those physical, psychological, social or organisational aspects of the job that require sustained physical and/or psychological effort and are therefore associated with certain physiological and/ 
or psychological costs (Demerouti \& Bakker, 2001). Job demands consist of three dimensions namely, quantitative job demands, emotional job demands, and mental job demands. The dimensions selected by authors are according to the dimensions of job demands previously used in a study by Peeters et al. (2005), followed by Notelaers et al. (2007), and Elst et al. (2016).

Quantitative job demands refer to work overload or work pressure or too much work to do in too little time (Peeters et al., 2005). Emotional job demands refer to the affective component of work and the degree to which one's work puts one in emotionally stressful situations (Peeters et al., 2005). Mental job demands refer to the degree to which work tasks call on a person to expend sustained mental effort in carrying out his or her duties (Peeters et al., 2005).

\section{Total Reward}

Total reward refers to a combination of financial and non-financial rewards made available to employees (Armstrong, 2013). According to Armstrong, the concept of total rewards describes an approach to reward management that emphasises the need to consider all aspects of the work experience of value to employees. It aims to blend the financial and non-financial elements of reward into a cohesive whole. Financial rewards consist of job-based pay which provides pay related to the value of the job, and person-based pay which provides rewards that recognise the individual's contribution (Armstrong, 2013). Non-financial rewards focus on the needs people have to varying degrees for recognition of achievement, personal growth, and acceptable working conditions (Armstrong, 2013).

\section{THEORETICAL FRAMEWORK AND PROPOSITIONS FOR STUDY}

According to a theoretical framework used in this study as depicted in Figure 1, employee engagement is the dependent variable and becomes the variable of primary interest for the authors. Job-related variables which constitute job characteristic and personal-related variables that include positive psychological capital are the independent variables. Job demands and total reward are postulated to have moderating effect on the relationship between the independent variables and dependent variables. 


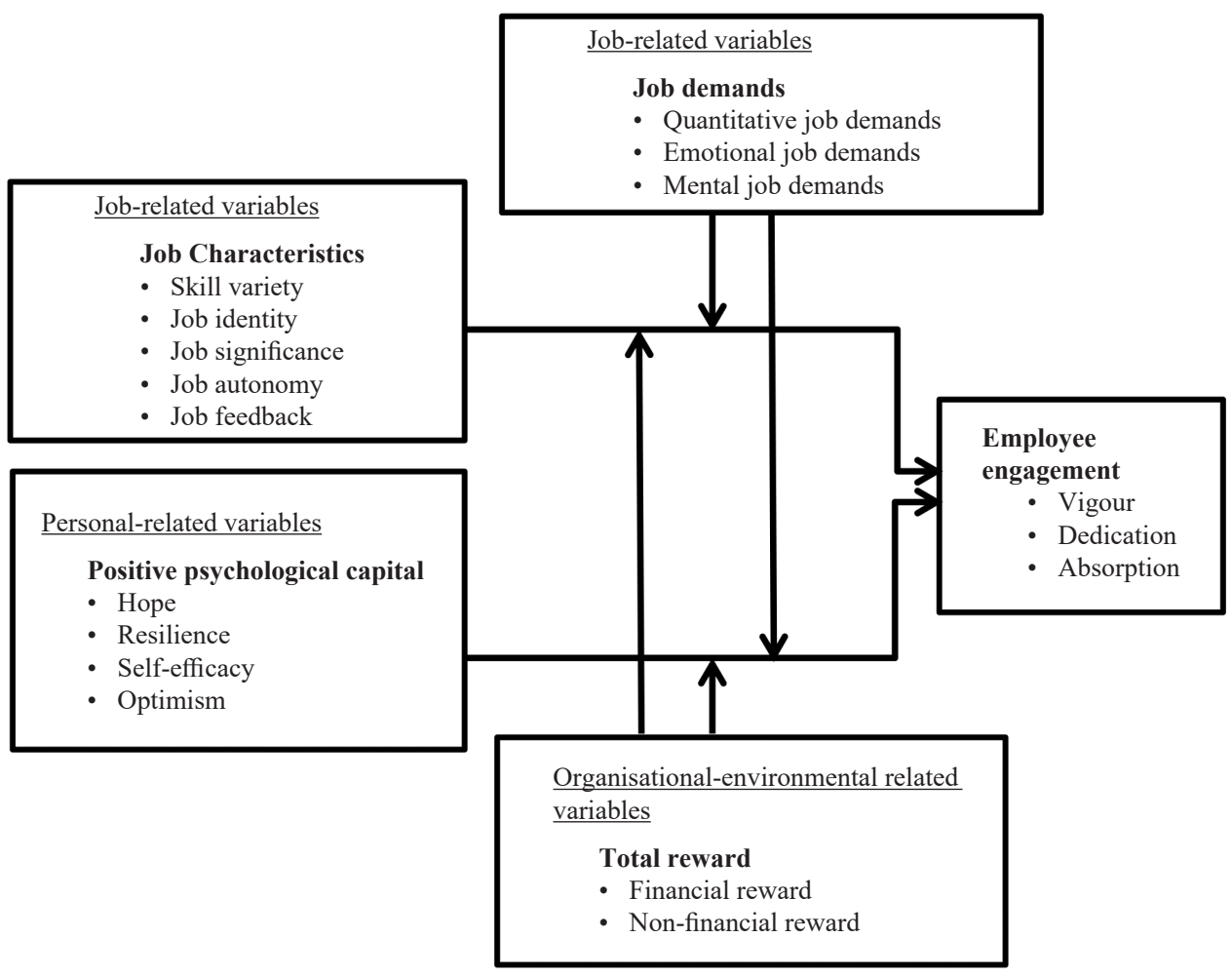

Figure 1. Theoretical framework of the study

JD-R theory provides a dominant theoretical basis for this study by explaining the relationship among independent variables (i.e., job characteristics and positive psychological capital) and employee engagement. Also explained by the JD-R theory are the roles of job demands as a moderator between the relationship among independent variables (i.e., job characteristics and positive psychological capital) and employee engagement. Building block of JD-R model consists of job environment and personal resources. Job environment was divided into two categories: job demands and job resources. To represent job resources, authors selected job characteristics due to the following criterions. First, job characteristics had motivational functions for employees in achieving work goals. Second, job characteristics potentially reduce job demands and the associated physiological and psychological costs. Third, job characteristics potentially stimulate personal growth, learning, and development of employees. All three criteria are fulfilled by job characteristics to represent job resources in the JD-R model. Positive psychological capital selected by authors to represent personal resources due to the similarities of characters given in the JD-R model for personal resources 
where it should be "a positive self-evaluation that are linked to resiliency and refer to individuals" sense of the ability to control and impact upon their job environment successfully. Authors selected job demands to represent other part of job environment in the JD-R model. Hence, it is proposed that:

Proposition 1: Job characteristics (skill variety, job identity, job significance, job autonomy, and job feedback) have a positive relationship with employee engagement (vigour, dedication, and absorption). Specifically, if job characteristics increase, then, employee engagement would increase, and vice-versa.

Proposition 2: Positive psychological capital (hope, resilience, self-efficacy, and optimism) has a positive relationship with employee engagement (vigour, dedication, and absorption). Specifically, if positive psychological capital increase, then, employee engagement would increase, and vice-versa.

As suggested by Baron and Kenny (1986), the authors introduced job demands and total reward as moderators because there is an unexpectedly weak or inconsistent relation between predictors (i.e., job characteristic and positive psychological capital) and a criterion variable (i.e., employee engagement). When job demands and total reward were introduced to act as a moderator, both variables give moderating effects to the focal variables (i.e., job characteristics and positive psychological capital). In other words, job demands and total reward act as moderators to the focal variables to give a moderating effect which change their direction and/or strength of a relation between independent or predictor variables (i.e., job characteristic and positive psychological capital) and a dependent or criterion variable (i.e., employee engagement). Operationally, moderators (i.e., job demands and total reward) interact with the predictors (i.e., job characteristic, and positive psychological capital) in such a way as to have an impact on the level of the dependent variable (i.e., employee engagement). A moderation effect is a causal model that postulates "when" independent variables (i.e., job characteristic, and positive psychological capital) most strongly (or weakly) causes a dependent variable (i.e., employee engagement), and according to Ro (2012), the independent variable's association with the dependent variable is stronger or weaker at different levels of the moderator variables (i.e., job demands and total reward).

According to Demerouti and Bakker (2011), within the JD-R model, the main role of job demands is seen in the health impairment process where it can be "bad" or "good" stressors. Bad stressor is when job demands become "hindrance" 
job stressors when it involves excessive or undesirable constraints that interfere with or inhibit an employee's ability to achieve valued goals. In other part, job demands become "good" stressors or "challenging" when they potentially promote the personal growth and achievement of the employee. As also highlighted in the Demerouti and Bakker (2011), the differentiation between "challenge" and "hindrance" job demands is still unknown as there is not sufficient empirical evidence on this issue. Moreover, whether the differentiation between these two kinds of demands is valid for every job is still an unclear issue. Hence, it is proposed that:

Proposition 3: Job demands (quantitative job demands, emotional job demands, and mental job demands) moderate the positive relationship between job characteristics and employee engagement (vigour, dedication, and absorption). Specifically, job demands increase the positive relationship between high job characteristics and employee engagement as compared to low job characteristics.

One of the studies that highlighted the moderating effects of job demands on the positive psychological capital as a focal variable which increase the employee engagement is highlighted by Bakker and Demerouti (2014). To test the boosting effect of personal resources, they hypothesised that weekly emotional job demands could facilitate the positive impact of personal resources (self-efficacy and optimism) on weekly work engagement. Using a sample from 63 nurses for three consecutive weeks, the results showed that emotional job demands strengthened the effect of personal resources on weekly work engagement, confirming that these demands act as a challenge for the nurses.

In other part, the moderating effects of job demands on positive psychological capital as a focal variable also found inconsistent findings. As highlighted by Hambrick, Finkelstein and Mooney (2005), researchers in organisational behaviour and industrial/organisational psychology have long been interested in the job demands placed on individuals, but obviously, the potential answers will vary for different kind of work. According to Yanchus et al. (2013), from studies conducted, it was found that the type of job demand determined whether employees were engaged in their jobs, where, less engagement occurred when a demand was seen as a hindrance (i.e., role ambiguity, job insecurity, constraints, and interpersonal conflicts), and more engagement occurred when a demand was perceived as a challenge (i.e., workload pressure, time pressure, and mental demand).

In other case, as highlighted by Xanthopoulou et al. (2007), employees with high levels of personal resources have greater mastery that helps them to deal more 
effectively with demanding job conditions, and in turn prevent them from negative outcomes such as exhaustion. In other word, job demands have a negative effect on the employees with high intrinsic work motivation where it strengthened the negative effect of job autonomy on work engagement, and they also found that the detrimental effects of workload and interpersonal conflict on exhaustion were more pronounced for employees having a strong prevention focus (i.e., who are concerned with obligations and responsibilities). Hence, it is proposed that:

Proposition 4: Job demands (quantitative job demands, emotional job demands, and mental job demands) moderate the positive relationship between positive psychological capital and employee engagement (vigour, dedication, and absorption). Specifically, job demands increase the positive relationship between high positive psychological capital and employee engagement as compared to low positive psychological capital.

According to Self-Determination theory used by authors to explain the existence of total reward in the theoretical framework, total reward is used as a motivational tool to "move" and channel employees' motivation in desired ways (Abdul Rahim \& Wan Daud, 2012). According to Hackman and Oldham (1976), the primary determinants of employee satisfaction are factors intrinsic to the work done (e.g., recognition, achievement, responsibility, advancement, personal growth, and competence) are called "motivators" because they are believed to be effective in motivating employees to superior effort and performance. The "motivators" highlighted by Hackman and Oldham (1976) is one of the components of total reward under categories of non-financial rewards (e.g., appreciation and recognition). Hence, it is proposed that:

Proposition 5: Total reward (financial reward and non-financial reward) moderates the positive relationship between job characteristics and employee engagement (vigour, dedication, and absorption). Specifically, total reward increase the positive relationship between high and low job characteristic and employee engagement.

The second reason for authors to introduce total reward as a moderator between a relationship of positive psychological capital and employee engagement in the JD-R model is due to the following explanation. As previously explained in the JD-R theory, in a motivational process of personal resources (i.e., positive psychological capital), the higher the individual's personal resources, the more positive the person's self-regard and the more goal self-concordance is expected to 
be experienced. As a result, individuals with goal self-concordance are intrinsically motivated to pursue their goals and confront with job demands, which will trigger higher engagement. But, from the best of authors' knowledge through literature on JD-R theory, no discussion was made on increasing the positive psychological capital of employees in facing the challenge of job demands. In this study, the authors introduced total reward as a moderator in the JD-R model to give a moderating effect on positive psychological capital as a focal variable, and in turn, employees can confront with job demands, and engaged with the work.

Positive psychological capital refers to the individual "motivational propensities" that accrue through positive psychological constructs of self-efficacy, optimism, hope, and resilience (Luthans \& Youssef, 2007). As discussed in Youssef and Luthans (2007), for positive psychological capital development, the developing employees should be supported, empowered, recognised, appreciated, rewarded, allowed to be authentic and innovative, and treated fairly for their positive psychological capital is likely to thrive and yield its desired outcomes. Authors postulated that total reward as a motivational tool with a combination of financial and non-financial rewards potentially could increase the "intrinsic motivation" of employees with positive psychological capital. In turn, they will be able to confront with job demands, and engage with the work. In other words, when the positive psychological capital of employees is low, employees are still motivated to confront high job demands, and engage with their works because the existence or moderating effects of total rewards (i.e., financial, and non-financial rewards) become a "mover" or "reasons" for employees to face the challenge of job demands and engage with the work. Hence, it is proposed that:

Proposition 6: Total reward (financial reward, and non-financial reward) moderates the positive relationship between positive psychological capital and employee engagement (vigour, dedication, and absorption). Specifically, total reward increase the positive relationship between high and low positive psychological capital, and employee engagement.

\section{CONCLUSION}

In conclusion, gaps discussed previously indicated that employee engagement matters and become the variable of primary interest (i.e., dependent variable) for the study. More academic research is needed to advance our understanding on the major factors influencing employee engagement for us to understand and benefit from it. Practitioners are looking to scholars and researchers for tools and 
techniques that are well grounded to creating, building, and maintaining employee engagement. In the following paragraphs, the authors explain, at the micro level, the significant contributions of the study to the practitioners and theories.

First, for practitioners, the findings added to the current body of knowledge, and it is useful for decision making at the management level especially on the issue of increasing the employee engagement in their organisation. Thus, by understanding the extent of predictors and moderators on employee engagement, then, the decision makers could carefully strategise the effective ways to improve their personalrelated, job-related, and organisational-environmental related factors. Specifically, the proposed theoretical framework is purposely used to predict employees' engagement by looking at important variables which play significant roles for employees in the Malaysia national automotive manufacturing companies, that could then guide decision makers and policy makers in the organisation to improve their quality of new vehicles produced by increasing the level of engagement among their employees especially from the production department.

Second, for theories, the findings added to the current literature and body of knowledge on the role of job demands. According to literature, roles of job demands on a job resources (i.e., job characteristics) in a JD-R theory were found inconsistence. This study examined the role of job demand can either be "bad" or "good" stressors for employees in the Malaysia national automotive manufacturing companies.

Third, another significant contribution for theories is that, the findings added to the current literature and body of knowledge on the moderating roles of job demands on the positive psychological capital. Currently, in the JD-R theory, there is limited evidence for the interaction between personal resource (i.e., positive psychological capital) and job demands.

Fourth, for Malaysian literature, the findings added to the current literature and body of knowledge for Malaysia studies on employee engagement. According to literature, authors found that local studies still fall short of investigating the forms of employee engagement and factors that influence employee engagement categorised as personal-related, job-related, and organisational-environmental related factors combining in one theoretical framework.

Finally, adding contribution for theories, the findings contributed to the current literature and body of knowledge on the roles of total reward to represent organisational-environmental related factor in the JD-R theory. Currently, to the best of the authors' knowledge through literature review, none of the previous 
studies has integrated the moderating roles of total reward in the JD-R theory. Authors postulated total reward potentially play a role as a "booster" or motivator for employees to engage especially when they have low job characteristic and/or low positive psychological capital.

\section{REFERENCES}

Abdul Rahim, M., \& Wan Daud, W. (2012). A proposed conceptual framework for rewards and motivation among administrators of higher educational provider in Malaysia. International Journal of Business and Commerce, 1(9), 67-78.

Ahlowalia, S., Tiwary, D., \& Jha, A. (2014). Employee engagement: A structured theoretical review. International Journal of Business and Management, 2(6), 309-317.

Aon Hewitt. (2015). 2015 trends in global employee engagement: Making engagement happen. New York: Aon Plc.

Aon Hewitt. (2017). 2017 trends in global employee engagement: Global anxiety erodes employee engagement gains. New York: Aon Plc.

Aon Hewitt. (2017). 2017 employee engagement trends: Malaysia scores fall for the first time in 4 years. AonHewitt.com. Retrieved 10 January 2017 from http://www. AonHewitt.com.

Armstrong, M. (2013). Armstrong's handbook of human resource management practice (13th ed.). London: KoganPage.

Bakker, A. (2015). APA handbook of career intervention. Washington, DC: American Psychological Association.

Bakker, A., \& Demerouti, E. (2007). The Job Demands-Resources model: State of the art. Journal of Managerial Psychology, 22(3), 309-328. https://doi. org/10.1108/02683940710733115

Bakker, A., \& Demerouti, E. (2014). Work and wellbeing. Wellbeing: A complete reference guide, vol. III. New York: John Wiley \& Sons.

Bakker, A., Schaufeli, W., \& Hox, J. (2009). Present but sick: A three-wave study on job demands, presenteeism and burnout. Career Development International, 14(1), 50-68. https://doi.org/10.1108/13620430910933574

Baron, R., \& Kenny, D. (1986). The moderator-mediator variable distinction in social psychological research: Conceptual, strategic, and statistical considerations. Journal of Personality and Social Psychology, 51(6), 1173-1182.

Demerouti, E., \& Bakker, A. (2011). The Job Demands-Resources model: Challenges for future research. Journal of Industrial Psychology, 37(2), 1-9. https://doi. org/10.4102/sajip.v37i2.974

Elst, T., Cavents, C., Daneels, K., Johannik, K., Baillien, E., Broeck, A., \& Godderis, L. (2016). Job demands-resources predicting burnout and work engagement among Belgian home health care nurses: A cross-sectional study. Nursing Outlook, 64, 542-556. https://doi.org/10.1016/j.outlook.2016.06.004

Gallup. (2017). State of the global workplace: Executive summary. Gallup.com. Retrieved 15 February 2017 from http://www.gallup.com/executivesummary. 
Guest, D. (2014). Employee engagement: A sceptical analysis. Journal of Organizational Effectiveness: People and Performance, 1(2), 141-156. https://doi.org/10.1108/ JOEPP-04-2014-0017

Hackman, J., \& Oldham, G. (1976). Motivation through the design of work: Test of a theory. Organizational Behavior and Human Performance, 16, 250-279.

Hambrick, D., Finkelstein, S., \& Mooney, A. (2005). Executive job demands: New insights for explaining strategic decisions and leader behaviors. Academy of Management Review, 30(3), 472-491.

Kahn, W. (1990). Psychological conditions of personal engagement and disengagement at work. Academy of Management Journal, 33(4), 692-724.

Luthans, F., \& Youssef, C. (2007). Emerging positive organizational behavior. Journal of Management, 33(3), 321-349. https://doi.org/10.1177/0149206307300814

Mache, S., Vitzthum, K., Klapp, B., \& Danzer, G. (2014). Surgeons’ work engagement: Influencing factors and relations to job and life satisfaction. The Surgeon, 12, 181-190. https://doi.org/10.1016/j.surge.2013.11.015

Markos, S., \& Sridevi, M. (2010). Employee engagement: The key to improving performance. International Journal of Business and Management, 5(12), 89-96.

Mehta, D., \& Mehta, N. (2013). Employee engagement: A literature review. Economia Seria Management, 16(2), 208-215.

National Consumer Complaints Centre (NCCC). (2011). 2011 annual consumer complaints report. Kuala Lumpur: National Consumer Complaints Centre (NCCC). Retrieved 10 January 2017 from http://www.nccc.org.my.

NCCC. (2012-2016). Annual consumer complaints report. Kuala Lumpur: NCCC. Retrieved 10 January 2017 from http://www.nccc.org.my.

Notelaers, G., Veldhoven, M., Witte, H., \& Vermunt, J. (2007). Construction and validation of the short inventory to monitor psychosocial hazards. Medecine Du Travail \& Ergonomie, XLIV, 10-17.

Peeters, M., Montgomery, A., Bakker, A., \& Schaufeli, W. (2005). Balancing work and home: How job and home demands are related to burnout. International Journal of Stress Management, 12(1), 43-61. https://doi.org/10.1037/1072-5245.12.1.43

Ro, H. (2012). Moderator and mediator effects in hospitality research. International Journal of Hospitality Management, 31, 952-961. https://doi.org/10.1016/j. ijhm.2011.11.003

Schaufeli, W. (2012). Work engagement: What do we know and where do we go? Romanian Journal of Applied Psychology, 14(1), 3-10.

Schaufeli, W., \& Taris, T. (2014). Bridging occupational, organizational and public health. Amsterdam: Springer Science and Business Media Dordrecht.

Upadyaya, K., Vartiainen, M., \& Salmela-Aro, K. (2016). From job demands and resources to work engagement, burnout, life satisfaction, depressive symptoms, and occupational health. Burnout Research, 3, 101-108. https://doi.org/10.1016/j. burn.2016.10.001

Wad, P., \& Govindaraju, V. (2011). Automotive industry in Malaysia: An assessment of its development. International Journal Automotive Technology and Management, 11(2), 152-171. 
Xanthopoulou, D., Bakker, A., Demerouti, E., \& Schaufeli, W. (2007). The role of personal resources in the Job Demands-Resources Model. International Journal of Stress Management, 14(2), 121-141. https://doi.org/10.1037/1072-5245.14.2.121

Yanchus, N., Fishman, J., Techlaw, R., \& Osatuke, K. (2013). Employee perceptions of job demands and resources and relationship to engagement. Applied Human Resources Management Research, 13, 1-23.

Youssef, C., \& Luthans, F. (2007). Positive organizational behavior in the workplace: The impact of hope, optimism, and resilience. Journal of Management, 33(5), 774 800. https://doi.org/10.1177/0149206307305562 